\title{
Empirical study of multicultural components of family values of Ukrainian and Crimean Tatar youth
}

\author{
Arzy Mambetova \\ Department of Developmental Psychology, Faculty of Psychology \\ Taras Shevchenko National University of Kyiv, Ukraine \\ Corresponding author. E-mail: arzy308@gmail.com, ORCID 0000-0001-8586-5078
}

Paper received 10.11.21; Accepted for publication 24.11.21.

https://doi.org/10.31174/SEND-PP2021-259IX101-15

\begin{abstract}
The article presents the results of an empirical study of multicultural components of family values of Ukrainian and Crimean Tatar youth. The specifics of the relationship between the formed family values and constituent orientations in this category of representatives of selected ethnic groups are analyzed. The article describes the stages of research of multicultural components of family values of Ukrainian and Crimean Tatar youth; empirical indicators are determined; the program of research of multicultural identification is substantiated, the author's technique is developed and the author's questionnaire "Scales of multicultural identification" is presented.
\end{abstract}

Keywords: multicultural identification, cultural modes, ethnocultural psychological features, multicultural components of family values, Ukrainian youth, Crimean Tatar youth.

Introduction. Value orientations are the core of national culture and mentality, so their study provides significant information on the basic features and dynamics of cultural development. Consideration of the role of value orientations in the socio-psychological space of youth is of particular importance for the humanities because it is in adolescence that a person is most sensitive to the latest social trends, so the value orientations of youth are indicators of socio-psychological change. In modern society, the problem of interethnic relations and the peculiarities of the perception of their nation is one of the most pressing. At the same time, a person is in a multicultural environment and faces situations of contradictions or even a dichotomy of choice between the systems of values and beliefs inherent in different cultures. Understanding these phenomena and studying the specifics of their psychological design should reflect one of the main tasks of modern psychological research.

The purpose of the article is to study the multicultural components of family values of Ukrainian and Crimean Tatar youth.

Materials and methods. The empirical study was performed in accordance with the standards of the algorithm of scientific psychological research.

The study of multicultural components of family values of Ukrainian and Crimean Tatar youth can be divided into several stages, each of which corresponded to the specific objectives of the study within this topic.

1) Theoretical analysis. The logic of the empirical study of the components of family values of Ukrainian and Crimean Tatar youth is based on a preliminary theoretical analysis of this problem, which is the first stage of the study. Accordingly, the analysis, systematization, generalization of the basic concepts and categories of study, their features and general characteristics, etc. are carried out.

2) Selection of methodological approaches to the organization of empirical research of multicultural components of family values of Ukrainian and Crimean Tatar youth. In analyzing the concept of multicultural components of family values, the main methodological approaches to the organization of empirical research are identified. The definition of this methodological orientation served as the main reference point for the creation of the author's methodology for the study of multicultural identification.

3) Design of diagnostic tools. Effective modern psychological methods for the study of multicultural components of family values of youth of different ethnic groups are selected: the questionnaire "Role expectations and harassment in marriage" Volkova A.N. [10]; Schwartz's method (Schwartz's value questionnaire) [12], Parental Attitude Research Instrument - PARI, questionnaire "Development of a holistic personality in modern change" Vlasova O.I., Cherbina V.S. [1; 7], method "Behavior of parents and attitudes of young people to them", method "Family Atom" [2].

The author's methodology and approach to the study of multicultural identification (author's questionnaire "Multicultural Identification Scales") have been developed [13].

4) Sample formation - the age limits of adolescence are determined; the psychological features of this age period are analyzed; groups of youth by ethnicity were singled out. All respondents who participated in the main part of the empirical study were distributed according to social and age characteristics. A total of 220 people were involved (110 Ukrainians, including 55 men and women, and 110 Crimean Tatars, including 55 men and women).

5) Conducting empirical research. The empirical study was conducted during 2019-2020 in two stages. At the first stage, a pilot study was conducted, aimed at analyzing the concepts and statements that form the basis of the created author's diagnostic tools for the study of multicultural identification. The second stage involved the main study - the diagnosis of multicultural components of family values of Ukrainian and Crimean Tatar youth.

6) Analysis and interpretation of the results of empirical research. At this stage, descriptive statistics procedures were used.

Results. In the course of empirical study of multicultural components of family values of Ukrainian and Crimean Tatar ethnic groups, the obtained data were investigated and analyzed and the following aspects were revealed:

o Distribution of the subjects according to their 
affiliation to cultural modes.

The analysis of the results of the author's questionnaire "Development of a holistic personality in the conditions of modern changes" showed the following distribution of the studied young Ukrainians by cultural systems (Figure 1).

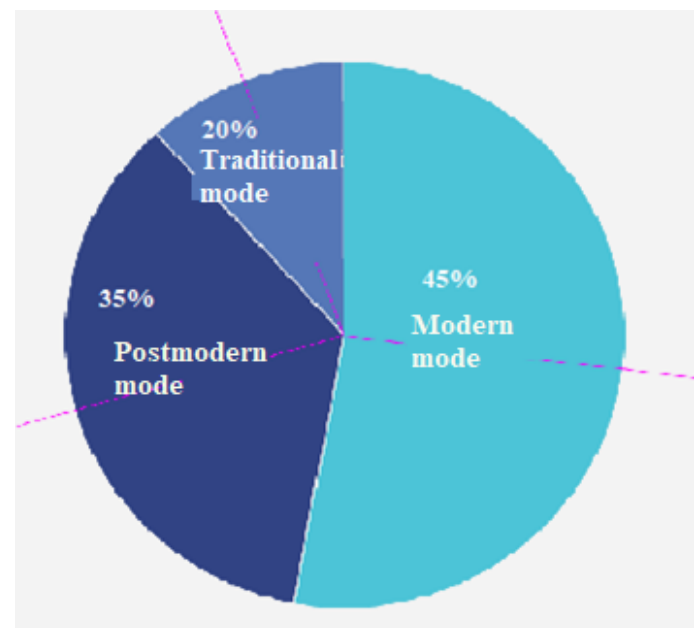

Figure 1. Distribution of the studied young Ukrainians according to cultural modes.

The distribution shows that modern $(45 \%)$ and postmodern $(35 \%)$ cultural modes predominate among young Ukrainians, which is due to the historical and socio-political peculiarities of the life of ethnic groups (industrialization and collectivization during the Soviet period significantly shook the traditional cultural system and gave grounds for the development of a modern cultural mode, and democratic processes and changes in the post-Soviet period contributed to the emergence and active development of a postmodern cultural mode.

The analysis of the results of the author's questionnaire "Development of a holistic personality in the conditions of modern changes" showed the following distribution of the studied young Crimean Tatars by cultural modes (Figure 2).

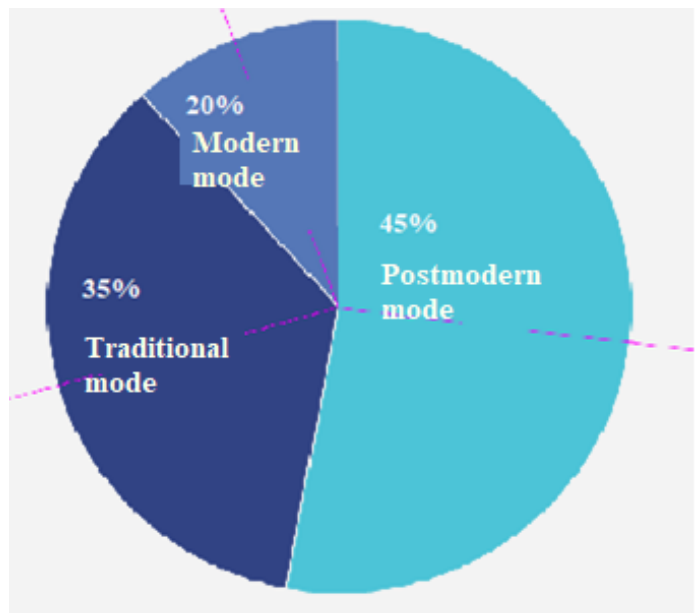

Figure 2. Distribution of the studied young Crimean Tatars according to cultural modes.

The distribution shows that postmodern (45\%) and traditional (35\%) cultural modes predominate among young Crimean Tatars, which is due to the historical and socio-political peculiarities of the ethnic life (attempted genocide and discrimination of the Crimean Tatar people during the Soviet period significantly shook his faith) representatives in the new industrial society and did not take root in the modern cultural mode, on the contrary strengthening the position of the traditional cultural system, which is associated with the preservation of values and traditional principles as a source of existence and life of the people and their representatives; development of postmodern cultural mode, which is associated with the development and expansion of opportunities for the people and their representatives).

o Qualitative characteristics of the value orientations of the studied (family values and values of cultural lifestyles to which they belong);

o Qualitative characteristics of the peculiarities of upbringing and perception of the family by the subjects;

o Qualitative characteristics of multicultural components of family values of the studied.

It was found that the sets of family values for members of the same cultural system, which are representatives of different ethnic groups, are virtually the same. They act as multicultural determinants of family values of young people. Ethnicity is manifested in the ways of embodying these values and establishing family life in accordance with the ideas of each individual ethnic group.

The following determinants will be inherent in the representatives of the traditional cultural structure: traditions, power, independence, self-realization, achievement of results, positive attitude.

The representatives of the modern cultural system will be characterized by the following determinant values: Kindness, Universalism, Independence, Self-realization, Achievement of results, Positive attitude, Positive interest, Autonomy, Intimacy.

The following determinant values will be inherent in the representatives of the postmodern cultural system: Hedonism, Kindness, Stimulation, Security, Achieving results, Positive attitude, Future orientation, Intimacy, Positive interest, Adequate self-esteem.

Peculiarities of interaction in the family sphere of young Crimean Tatars and Ukrainians - representatives of different cultural systems, which are regarded by them as negative, were also revealed.

The work on rethinking these negative perceptions and their positive transformation was continued in the format of author's training and will be described in the following articles.

Conclusions. The scientific novelty of the study exists due to the relatively small percentage of elaboration of this issue in modern domestic scientific psychology and scientific psychology of CIS countries and taking into account the relatively high degree of interest in multicultural values $\mathrm{n}$ ethnic communities and modern communities of different countries, among representatives of Western psychological schools in Europe and the United States.

Nowadays, the topic of psychological characteristics of representatives of ethnic communities of Ukraine is especially relevant. Therefore, we can assume that the level of novelty and scientific significance of this study is sufficient to determine the feasibility of its further development.

Reliability and reliability of research results will be 
provided by methodological substantiation of its initial provisions, use of valid and reliable diagnostic techniques, adequate to the purpose and tasks of research; a combination of quantitative and qualitative analysis of empirical data; application of methods of mathematical statistics with the involvement of modern data processing programs; representativeness of the sample.

\section{REFERENCES}

1. Ananova I. V., Vlasova O. I., Hulenko A. S., Danyliuk I. V., Fadieieva K. - M., Shcherbyna V. L. (2015) The types of personal integrity of the modern Ukrainian multicultural society Socio-economic sciences and challenges of modern technology and planetary communication: International Conference on ICT Management for Global Competitiveness and Economic Growth in Emerging Economies ICTM 2015 : http://papers.ssrn.com Retrieved from URL: http://papers.ssrn.com/sol3/cf_dev/AbsByAuth.cfm?per_id=2 469326.

2. Bulatevich N., Mambetova A. (2018). Psychological peculiarities of parenthood apprehensions of Ukrainians and Crimean Tartars. International Journal of Education \& Development, 1, $13-24$.

3. Ryan R., \& Deci E. (2000). Self-detenrrination theory and the facilitation of intrinsic motivation, social development, and well-being. American Psychology. Vol. 55 (1). P. 68-78.

4. Ryff, C.D., \& Keyes, C.L.M. The structure of psychological well-being revisited // Journal of Personality and Social Psychology, 1995, 69, 719-727

5. Ryff, C.D., \& Singer, B. Human health: new directions for the next millennium // Psychological Inquiry, 1998, 9, 69-85.

6. Shykovets S.O., Mambetova A.A. (2018). Psychological features of the representatives' identity in the regional communitiesof Ukraine and Poland. Naukovyi Visnyk Khersonskoho Derzhavnoho Universytetu. Psykholohiia Scientific Bulletin of Kherson State University. Psychology,
$3,1,142-148$.

7. Vlasova O.I. (2019). Influence of internet dependency on young people self-actualization. Socialization \& Human Development: International Scientific Journal, 1, 1, 5-12.

8. Boatswain, S., \& Lalonde, R. (2000). Social identity and preferred ethnic/racial labels for blacks in Canada. Journal of Black Psychology, 26, 216-234.

9. Cameron, J. (2004). A three factor model of social identity. Self and Identity.

10. Cameron, J., \& Lalonde, R. (2001). SOCIAL identification and gender related ideology in women and men. British Journal of Social Psychology, 40, 59-77.

11. Bichler, S., Albert, I., Barros, S. et al. (2020). Exploring Cultural Identity in a Multicultural Context - the Special Case of Luxembourg. $\mathrm{Hu}$ Arenas 3. 310-330. https://doi.org/10.1007/s42087-019-00090-w

12. Berry, J. W. (2017). Theories and models of acculturation. In S. J. Schwartz \& J. B. Unger (Eds.), Oxford library of psychology. The Oxford handbook of acculturation and health (pp. 15-28). New York: Oxford University Press.

13. Mambetova, A., \& Vlasova, I. (2021). Multicultural components of family values of Ukrainian and Crimean Tatar youth: author's questionnaire "Scales of multicultural identification". Conference proceedings. VII International research \& training conference. Public health social, educational and psychological dimensions. 17 July 2021. Lublin, Poland. 